\title{
RELATO DE EXPERIÊNCIAS DO ProJeto ENCONTRO de SABERES NA UfRR E NA
}

\author{
FURG \\ LETICIA CAO PONSO ${ }^{1}$ \\ PABLO ALBERNAZ ${ }^{2}$
}

\begin{abstract}
RESUMO
Este artigo propõe uma reflexão entre experiências do projeto Encontro de Saberes em duas universidades federais brasileiras: as localizadas mais ao Norte (UFRR) e mais ao Sul do Brasil (FURG), distantes cerca de 5.533 quilômetros uma da outra. Ancorados nos pressupostos teórico-metodológicos do Projeto Encontro de Saberes (INCTI-CNPq), buscamos descrever a implementação desse projeto na UFRR e FURG e refletir sobre o seu papel na recriação de trajetórias acadêmicas de graduandos e pós-graduandos, mestres tradicionais e docentes, bem como sobre a importância dessa disciplina para uma política da permanência e conclusão de cursos desses mesmos estudantes.
\end{abstract}

\author{
PALAVRAS-ChAVE \\ Ações afirmativas; Encontro de Saberes; Universidades. \\ REPORT OF EXPERIENCES OF THE MEETING OF KNOWLEDGES PROJECT AT UFRR AND FURG
}

\begin{abstract}
This article proposes a reflection between experiences of the Meeting of Knowledges Project in two Brazilian federal universities: those located more to the North (UFRR) and more to the South of Brazil (FURG), about 5,533 kilometers apart of each other. Anchored in the theoretical and methodological assumptions of the Meeting of Knowledges Project (INCTI-CNPq), we seek to describe its implementation at UFRR and FURG and reflect on its role to the recreation of academic trajectories of undergraduate and graduate students, traditional masters and teachers, as well as on the importance of this discipline for these student's permanence policy and courses conclusion.
\end{abstract}

\section{KEYWORDS \\ Affirmative actions; Meeting of knowledges; Universities.}

\section{RAPPORT D'EXPÉRIENCES DU PROJET RENCONTRE DE SAVOIRS À L'UFRR ET À LA FURG}

\section{RÉSUMÉ}

Cet article propose une réflexion entre les expériences du projet Rencontre de Savoirs dans deux universités fédérales brésiliennes: celles situées plus au nord (UFRR) et plus au sud du Brésil (FURG), distantes d'environ 5533 kilomètres. Ancrés dans les hypothèses théoriques et méthodologiques du Projeto Rencontre de Savoirs (INCTI-CNPq), nous cherchons à décrire la mise en œuvre de ce projet à l'UFRR et à la FURG et à réfléchir sur son rôle dans la recréation des trajectoires académiques des étudiants de premier cycle et des cycles supérieurs, des maîtres traditionnels et des enseignants, ainsi que sur l'importance de cette discipline pour une politique de permanence et de conclusion des cours de ces mêmes étudiants.

\footnotetext{
${ }^{1}$ Doutora em Teoria e Análise Linguística pela Universidade Federal Fluminense (UFF), com estágiosanduíche na Universidade Eduardo Mondlane - Moçambique. Professora Adjunta da Universidade Federal do Rio Grande (FURG).

2 Doutor em Antropologia pela Eberhard Karls Universität Tübingen (EKU), Alemanha. Professor Adjunto do curso de Antropologia da Universidade Federal de Roraima (INAN-UFRR).
} 


\section{MOTS-CLÈS}

Acction positives; Rencontre de Savoirs; Universités.

\section{INFORME DE EXPERIENCIAS DEL PROYECTO ENCUENTRO DE CONOCIMIENTOS EN UFRR Y FURG}

\section{RESUMEN}

Este artículo propone una reflexión entre experiencias del proyecto Encuentro de Saberes en dos universidades federales brasileñas: las ubicadas más al norte (UFRR) y más al sur de Brasil (FURG), a unos 5.533 kilómetros de distancia. Anclados en los supuestos teóricos y metodológicos del Projeto Encuentro de Saberes (INCTI-CNPq), buscamos describir la implementación de este proyecto en la UFRR y FURG y reflexionar sobre su rol en la recreación de trayectorias académicas de estudiantes de graduación y posgrado, maestros tradicionales y docentes, así como sobre la importancia de esta disciplina para una política de permanencia y conclusión de cursos de estos mismos alumnos.

\section{PALABRAS CLAVE}

Acciones afirmativas; Encuentro de Saberes; Universidades. 


\section{INTRODUÇÃO}

Este artigo consiste em um relato de duas experiências baseadas na proposta teórico-metodológica e política do Projeto Encontro de Saberes (INCTI-CNPq), realizadas na Universidade Federal de Roraima (UFRR), no extremo norte do país, e na Universidade Federal do Rio Grande (FURG), no extremo meridional. Tal projeto promove uma experimentação pedagógica transdisciplinar motivada por resgates do mundo dos saberes tradicionais, de matrizes indígenas, africanas e de outras comunidades, acumulados durante séculos no Brasil e transmitidos por mestres e mestras de notório saber convidados a lecionar nas universidades brasileiras.

Desde que se ampliou a política de acesso ao ensino superior brasileiro por meio de ações afirmativas, um dos principais desafios enfrentados pelo público de alunos envolvidos diz respeito a insuficiência de uma política institucional para sua integração a partir de suas próprias referências pregressas de comunicação e interação, bem como suas formas originais de pensar em suas línguas, culturas e cosmologias. Desse modo, o ponto de partida que motiva esta reflexão é a nossa busca por caminhos possíveis no acompanhamento pedagógico intercultural decorrente dessa nova realidade apresentada a tais estudantes, por meio de práticas institucionalizadas que promovam transformações na política de permanência desses sujeitos na universidade, mas também transformações na estrutura da própria universidade.

Рara essa discussão, importa mencionar que a academia, espaço tradicionalmente legitimado de produção e propagação de conhecimentos, é também, em certa medida, local (re)produtor de violências e marcado por discriminação contra grupos historicamente subalternizados em diferentes contextos. As denúncias envolvendo violências epistêmicas e pedagógicas têm se ampliado a partir do confronto intercultural instituído devido à permanência na esfera universitária desses "sujeitos coletivos de direitos", como indígenas, quilombolas, negros, camponeses, ciganos, pescadores artesanais, povos da floresta, povos de terreiro, refugiados, pessoas com deficiência, e outros grupos e comunidades. Ainda que haja esforços para criar propostas pedagógicas interculturais na esfera universitária, em geral elas têm sido obstaculizadas por uma estrutura administrativa acadêmica predominantemente monocultural e monológica, pouco flexível no que tange à absorção de experiências outras, distintas dos padrões normativos do sistema nacional de educação superior (BARROSO-HOFFMANN, 2005; FREITAS, 2015; SITO, 2016; CESAR; MAHER, 2018; CARVALHO, 2018).

Ainda refratária em relação às transformações estruturais que a presença desses grupos demanda, a universidade resiste, e, conforme a realidade nos mostra, o enfrentamento das diferentes violências ainda ocorre por meio de iniciativas pontuais, 
muitas vezes vinculadas a coletivos estudantis autônomos ou a projetos de pesquisa individuais. Desse modo, as relações sociais que se estabelecem na esfera acadêmica entre os diferentes sujeitos que a compõem - professores/as, técnicos/as-administrativos/as, estudantes de graduação e pós-graduação, funcionários/as terceirizados/as - apresentam-se alicerçadas em um modelo de universidade eurocentrado, colonizador e desenraizado dos saberes tradicionais e da territorialidade que ocupa (CARVALHO, 2018).

"[...] Se existem saberes indígenas e afro-brasileiros considerados agora obrigatórios para a formação de nossos estudantes universitários, os professores capacitados para transmiti-los com maior autoridade e legitimidade intelectual são justamente os mestres e mestras que os reproduzem, recriam e transmitem para os demais membros das suas comunidades, seguindo tradições seculares (que são, na maioria das vezes, mais antigas que a própria tradição universitária brasileira)". (CARVALHO, 2016, p. 6).

Isto posto, o objetivo geral deste artigo é realizar um exercício de reflexão acerca de duas experiências no âmbito deste projeto, distantes geograficamente, mas em permanente diálogo, buscando pensar sobre o papel do Encontro de Saberes na recriação de trajetórias acadêmicas de graduandos e pós-graduandos, mestres tradicionais e docentes, descrever cada uma de nossas experiências e, por fim, tecer uma argumentação em defesa da importância dessa disciplina para uma política da permanência e conclusão de cursos desses mesmos estudantes.

\section{Projeto EnCONTRO de SABERES E A CONSTRUÇÃO de UMA EDUCAÇÃO SUPERIOR AFIRMATIVA, INTERCULTURAL, PLURIEPISTÊMICA E DESCOLONIZADORA}

Observa-se nas universidades brasileiras um enorme desconhecimento acerca dos saberes tradicionais, da multiplicidade de línguas, de repertórios mítico-poéticos e musicais, de artes e ofícios em extinção, da sabedoria de guardiões que são também protetores da natureza e das comunidades indígenas, quilombolas, afro-brasileiras, ribeirinhas, etc. Tal desconhecimento, certamente, é dos principais responsáveis para que o preconceito étnicoracial se incruste ainda mais nas entranhas do tecido social e foi a motivação principal da Lei 11.645/2008, que torna obrigatório o ensino de história e cultura afro-brasileira e indígena, ainda pouco observada nos currículos das Licenciaturas nas IFES, e da Lei 12.711/2012, a Lei de Cotas no ensino superior.

O ingresso dos povos tradicionais no ensino superior brasileiro faz parte de uma luta histórica que originou legislações voltadas à garantia do exercício de seus direitos culturais diferenciados. No entanto, as decisões em relação às políticas educacionais para estudantes indígenas e quilombolas no ensino superior são administradas em uma arena de interesses que muitas vezes reproduzem sua subalternidade (BARROSO-HOFMANN, 2005). Tais políticas dão continuidade ao processo colonizador que significou o etnocídio e linguicídio de 
centenas de sociedades ameríndias, excluiu a população negra das primeiras escolas e universidades brasileiras e até hoje pressupõe a destruição cultural e a submissão dos sujeitos colonizados, suas línguas e culturas.

Por outro lado, tais estudantes têm apresentado um comportamento de resistência, ativismo e protagonismo face a seus direitos e a um letramento acadêmico calcado em uma cosmovisão cultural imanente, que produz sentidos em vários gêneros discursivos: orais, corporais, escritos, artísticos, espirituais, artesanais, militantes.

No intuito de ponderar sobre o preparo que, como docentes, devemos ter para atuarmos como profissionais culturalmente sensíveis a essa área transicional, ou fronteiriça (na qual há conflitos, tensões, sincretismos vários), e acompanharmos a transformação nas IES brasileiras nos últimos anos, vinculamos nosso trabalho ao Projeto Encontro de Saberes.

Nas últimas três décadas, vivenciamos um processo de debate e reflexão acerca da plurivocalidade e da diversidade constituintes da sociedade brasileira que derivou na elaboração de uma série de leis "descolonizadoras", favoráveis especialmente à educação indígena. Podem-se citar, entre muitas políticas e leis reparatórias, as seguintes: a) criação da Coordenação Geral de Educação Escolar Indígena a partir de 2004, com expressivos recursos a ela destinados; b) fortalecimento da Comissão da Educação Escolar Indígena junto ao MEC, em diálogo com o Inep e com a Funai; c) criação da Comissão Nacional de Apoio à Produção de Materiais Didáticos Indígenas - Capema; d) Lei 12.155/2009, cujo artigo 90 determina: "Fica o Fundo Nacional de Desenvolvimento da Educação (FNDE) autorizado a conceder bolsas para alunos e professores vinculados a projetos e programas de ensino e extensão voltados a populações indígenas, quilombolas e do campo"; e) realização da I Conferência de Educação Escolar Indígena (2009); f) Prolind, Programa de Apoio à Formação Superior e Licenciaturas Interculturais Indígenas; g) Programa de Iniciação à Docência - PibidDiversidade, em apoio a estudantes indígenas que cursam a Licenciatura Intercultural Indígena (Prolind) (PONSO, 2018).

Paralelamente, iniciou-se um significativo movimento no sentido de minimizar as desigualdades que afetam a população negra do ponto de vista de sua histórica exclusão dos processos educacionais no Brasil. O Conselho Nacional de Educação introduziu, na Lei 9.394/1996 das Diretrizes e Bases da Educação Nacional, a Lei 10.639, de 9 de janeiro de 2003, que inclui no currículo oficial de toda a rede de ensino a obrigatoriedade do estudo da História da África e da Cultura afro-brasileira e africana, do ensino das relações étnico-raciais e do estudo das comunidades remanescentes de quilombos. Quatro anos mais tarde, essa mesma lei foi alterada pela Lei 11.645, de 10 março de 2008, por meio da qual se acrescenta no currículo oficial a obrigatoriedade da temática indígena, além da africana e afro-brasileira.

Quanto à educação quilombola, especificamente, a Conferência Nacional de Educação (CONAE), de 2010, incluiu a discussão sobre o direito das comunidades 
remanescentes de quilombos à educação. Como resultado do debate, o Parecer CNE/CEB 07/2010 e a Resolução CNE/CEB 04/2010 incluem a educação escolar quilombola como modalidade nas Diretrizes Curriculares Gerais para a Educação Básica. Porém, somente em 2012 foram dispostas as Diretrizes Curriculares Nacionais para a Educação Escolar Quilombola na Educação Básica por meio da Resolução 08/2012 do CNE. Em 2014, foi aprovado o Plano Nacional de Educação, que prevê políticas específicas para as comunidades quilombolas.

Contudo, foi somente a adoção de cotas raciais no ensino superior, inicialmente pela Universidade Estadual do Rio de Janeiro (UERJ) e pela Universidade Estadual do Norte Fluminense Darcy Ribeiro (UENF) ao fim de 2001 e, a seguir, pela Universidade de Brasília (UnB) em 2003, que trouxe as ações afirmativas para o centro da pauta midiática, nove anos antes da implementação da Lei 12.711, de 29 de agosto de 2012, que garante a reserva de $50 \%$ das matrículas por curso nas universidades federais e institutos federais de educação, ciência e tecnologia a alunos oriundos integralmente do ensino médio público. Dentro desses $50 \%$, a reserva de vagas destinadas a pretos, pardos e indígenas segue a proporção desses grupos, conforme o censo do IBGE, no Estado correspondente à instituição de ensino.

Em linhas gerais, os opositores às ações afirmativas como uma política social reparatória e compensatória argumentam que o acesso ao ensino superior seria um problema de classes sociais, e não de cunho étnico-racial. Além disso, posições alarmistas sugerem que a excelência acadêmica e a qualidade do ensino poderiam ser comprometidas. Tal postura, na opinião de Silva e Silvério (2003), apenas consolida uma aristocracia intelectual convicta de superioridade e continuará trazendo impactos nefastos para o grupo discriminado, como demonstram sistematicamente indicadores sociais. Para os autores, o desafio é "redefinir os critérios de excelência acadêmica e científica, sem perder o rigor que é garantido por teorias educacionais e científicas" (SILVA; SILVÉRIO, 2003, p. 29).

Nesse sentido, uma recente mudança de paradigma e de concepção de ensino instituiu-se no movimento surgido com a implementação do Projeto Encontro de Saberes, em 2010, uma iniciativa do Instituto Nacional de Ciência e Tecnologia de Inclusão no Ensino Superior e na Pesquisa (INCTI), sediado na Universidade de Brasília (UnB), o qual integra o Programa de Institutos Nacionais de Ciência e Tecnologia do Conselho Nacional de Desenvolvimento Científico e Tecnológico (CNPq) do Brasil. O projeto, já implementado em diversas universidades brasileiras e também na Colômbia, convida os/as mestres/as dos saberes tradicionais latino-americanos a atuarem como professores nas universidades (CARVALHO, 2015; 2018). Seu idealizador, o antropólogo José Jorge de Carvalho, questiona:

"Afinal, quem irá ensinar as histórias e as culturas africana, afro-brasileira e indígena para os jovens da escola básica e da universidade? O único modo de descolonizar a leitura eurocentrada dos negros e dos indígenas é trazendo os mestres e mestras dessas comunidades para, junto com os doutores negros e indígenas, ensinarem os 
conteúdos das leis aos estudantes universitários, já que estes serão os futuros professores dessas disciplinas nos ensinos básico e médio. Assim, uma nova geração acadêmica terá sido inserida na transmissão direta dos saberes afro-brasileiros e indígenas, que serão a partir de agora representados também pelos mestres e mestras em uma relação direta, face a face, com os seus discípulos" (Carvalho, 2018, p. 82).

Em suma, como defende Carvalho, as cotas para negros e indígenas garantidas pela Lei 12.711 e a inclusão dos saberes afro-brasileiros e indígenas nos currículos garantidos pelas Leis 10.639 e 11.645 - as duas primeiras revoluções para uma academia pluriepistêmica no Brasil - levaram a uma terceira revolução: mestres e mestras tradicionais, detentores de sabedorias ancestrais, foram levados às universidades para ministrarem aulas, participarem de bancas, envolverem-se em projetos de pesquisa, desafiando a abertura das IES para os diálogos interepistêmicos em distintas áreas do saber.

\section{ENCONTRO DE SABERES NA UFRR}

O projeto Encontro de Saberes começou a ser pensado na UFRR a partir do seminário "Antropologia e Encontro de Saberes: Diálogos Interepistêmicos", que ocorreu em outubro de 2017 e contou com a presença de diversos professores e pesquisadores ligados ao projeto em outras universidades, bem como mestres e mestras de saberes tradicionais. A partir desse evento em 2017, deu-se início às discussões sobre a melhor maneira de oferecer a disciplina Encontro de Saberes no âmbito da UFRR. Durante os debates sobre a reforma do Projeto Político Pedagógico (PPP) do bacharelado em antropologia social, foi aprovada a criação da disciplina "Encontro de Saberes: artes e ofícios das populações tradicionais". Embora a reforma do PPP não tenha sido ainda concluída, a disciplina foi ofertada no primeiro semestre de 2019 como Tópico Especial Livre, dividido em cinco partes oferecidas ao longo de cinco semanas, com aulas às sextas à noite e aos sábados durante manhã e tarde, totalizando 12 horas cada um dos módulos. Esse formato da disciplina pareceu ser o mais adequado nessa primeira oferta, visto que o curso de antropologia é noturno e, após diversas conversas com os mestres convidados, avaliamos que parte das aulas deveriam ser realizadas fora da universidade. Em 2021 o curso foi novamente ofertado, dessa vez como disciplina regular e projeto de extensão, às terças e sextas-feiras, como "roda virtual de conversas", em formato remoto devido à pandemia de covid-19, o que possibilitou também que mestres e mestras de várias partes do Brasil pudessem participar.

A primeira experiência da disciplina "Encontro de Saberes: artes e ofícios das populações tradicionais" teve início nos dias 7 e 8 de junho de 2019, com o módulo "Artes e Ofícios", ministrado por Vera Aparecida de Souza. Vera de Oxossi nasceu no Rio de Janeiro e com trinta e dois anos iniciou-se no candomblé Angola, recebendo o nome de Mutalē. Um ano depois mudou suas águas para o candomblé Ketu, e recentemente iniciou-se na doutrina 
do Ifá Nigeriano, tendo recebido o nome de Ifaseyi (Ifá me dá coisas boas). Vera de Oxossi atende muitas pessoas através do seu jogo de búzios (Ifá) e, além de sua vivência na religião, é artista plástica e técnica em enfermagem. Essa sua última formação the possibilitou uma experiência entre os Yanomami, que marcou profundamente sua arte e sua visão sobre a vida e a religiosidade (IFASEYÍ, 2021).

Sua aula inicial ocorreu na sexta à noite no auditório do Instituto de Antropologia e a segunda aula no sábado durante o dia, em sua casa de religião. Diante de plateia interessada e participativa, Vera ensinou aos alunos como as religiões de matriz afro entendem os Orixás, os caboclos, e a relação desses com a natureza. De acordo com Vera, os Orixás são divindades que estão anos-luz distantes de nós. Eram pessoas que viraram mitos, desencarnaram há muito tempo atrás, e por isso para que eles possam vir à terra é necessária a realização de sacrifícios, cantos, toques de tambor, rezas. Diferentes dos Orixás são as entidades da umbanda, os pretos velhos, caboclos, que segundo ela desencarnaram há poucas centenas de anos e por isso estão mais próximos dos vivos, sendo menos difícil de serem invocados devido à sua proximidade espaço-temporal.

Na aula de sábado, a arte de Vera de Oxossi (influenciada pela vivência junto aos Yanomami) foi um elemento importante para a transmissão dos ensinamentos sobre a religiosidade afro-brasileira. Um de seus quadros dispostos em sua casa retratava Exú e serviu para que Vera descrevesse essa entidade como "o homem que olha para todos os lados" e sabe tudo que nós humanos fazemos, pensamos, vemos e ouvimos. O quadro de Vera retrata Exú como uma figura agigantada e fálica, com um pênis no lugar do pescoço e com os búzios do ifá no lugar dos seus olhos. Essa imagem do pênis é retratada no quadro por ser Exú o responsável pela energia da libido e pelo seu movimento. Vera falou dos muitos lugares em que vive Exú, como as encruzilhadas e a porta do céu. Explicou que por isso ele faz o trânsito entre o mundo dos vivos, dos mortos e dos Orixás.

Vera fez uma apresentação dos lugares de firmamento de sua casa, explicando através deles os Orixás e entidades com as quais trabalha, com ênfase especial no jogo de búzios, com o qual atende clientes em seu dia-a-dia, e sobre a arte e sua experiência com os Yanomami. Ao fim da aula, a mestra ofereceu aos alunos vatapá, comida oferecida para lansã (podendo também ser ofertada à Xangô), e Omolocum, comida destinada a Oxum. Todos comeram com a mão e com a porção servida em folhas, conforme a tradição do candomblé. Em um gesto de gentileza e arte, Vera ainda confeccionou diversas bonecas de fuxico em homenagem às suas ancestrais, e distribuiu aos alunos como lembrança de sua aula.

O segundo módulo, "Plantas e Espíritos", ocorreu nos dias 14 e 15 de junho, no Instituto de Antropologia e na Casa Ilê Oba D’Alaguinan, primeira comunidade de terreiro de tradição Mina Jeje-Nagô no Estado de Roraima, fundada em 1992. As aulas foram ministradas pela dona da casa, Maria da Graças Pereira Bahia, mais conhecida como Yatylyssa. 
Mãe Yatylyssa é sacerdotisa da Nação Mina Jeje Nagô Fôn, iniciada no Candomblé por Orlando Machado da Silva, conhecido como Orlando Bassú e tendo como nome de santo Dayko Urubitauá, na casa Abassá Afro Brasileiro Lego Xapanã, sediada em Belém (PA).

A aula de Yatylyssa retomou e aprofundou alguns conceitos gerais do candomblé apresentados na aula de Vera, porém com uma ênfase maior nos rituais de iniciação, no poder das plantas e suas relações com os espíritos. Para Yatylyssa, sem erva não existe vida, pois ela é o "sangue vegetal" fundamental para a liturgia do candomblé. Com as ervas são preparados os banhos, os unguentos, os chás, e é possível saber sobre a energia de cada Orixá. A mestra também falou das diferenças entre os Orixás e as demais entidades que estariam mais próximas do contato com as pessoas que visitam as casas, e são os Exús, Caboclos, e a "organização social dos encantados" que existe dentro da nação Nagô, da qual ela faz parte. Esses encantados são diferentes tipos de entidades, como os turcos, os bandeirantes, os juremeiros, os codoenses, e encantados que, segundo ela, migraram para Roraima através da chegada dos maranhenses, como os boiadeiros.

Ao apresentar aos alunos os locais da casa, Yatylyssa falou do desconhecimento e do preconceito com relação às entidades femininas, denominadas Pombas Giras, que não são espíritos de prostitutas, como muitas pessoas que desconhecem a religião pensam, mas são Exús em forma feminina, com sensibilidade e conhecimento, detentoras do poder feminino e da autoconfiança. Para Yatylyssa, um dos aspectos mais positivos do Encontro de Saberes na UFRR foi buscar uma aproximação com o candomblé em um local predominantemente indígena, onde se pensa que não existiu influência negra, mas que com o garimpo e a chegada dos maranhenses passou a receber forte influência das religiões de matriz afrobrasileira.

O terceiro módulo, "Artes da Cura", ocorreu nos dias 21 e 22 de junho, no Instituto de Antropologia e na casa Abasa NGola Ngunzu Tata Bokùlê dia NGongombila, primeira comunidade de terreiro de tradição Angola de Boa Vista, Roraima, fundada em 1989, por Carlos Alberto de Souza Fournier Filho, mais conhecido como Tata Bokùlê. Tata foi iniciado no Candomblé Nação Angola pelo Tata dia Nkisi Mutalembê (Jose Wilson Falcão Real) para o nkisi (orixá) NGongombira, recebendo a dijina (nome) Tata Bokùlê.

Em sua aula, Tata Bokùlê enfatizou que embora autores como Roger Bastide e Pierre Verger tenham levado os conhecimentos do candomblé para a academia através de livros, esses saberes são assentados na oralidade, reforçando a importância desses conhecimentos estarem na universidade, principalmente no contexto atual de racismo religioso.

Para introduzir o tema de sua aula, Bokùlê falou da importância de Omolu (Obaluaê, ou Kavungo, outros nomes desse Orixá) no candomblé. De acordo com o sábio, ele é o Orixá que vem da terra, trabalha a terra e, por isso, "entende quem pisa nela". Para o sábio, Omolu 
é o senhor das vibrações, sendo através da vibração espiritual que ele faz suas curas. Рara essas curas, o jogo de búzios é fundamental, uma vez que possibilita ao conhecedor saber o que está fora do equilíbrio e pode desencadear doenças nas pessoas ou problemas numa comunidade. "Candomblé não é apenas uma religião, é um caminho de cura”, afirmou Bokùlê ao falar sobre Obaluaê como um médico. Em sua casa, o sábio mostrou como se realiza limpeza para retirar a energia negativa das pessoas com as pipocas de Obaluaê e a palma do dendezeiro, a folha de Ogum. Assim como nos módulos anteriores, o mestre narrou diversos mitos sobre os Orixás, bem como relacionou os alimentos com os ritos de cura. Bokulê também tratou das tentativas de grupos evangélicos de criminalizar os rituais sacrificiais de religiões de matriz afrobrasileira. Contra o desconhecimento das pessoas sobre os fundamentos do candomblé, o mestre propõe o termo "sacralização" ao invés de "sacrifício", afirmando que nas religiões de matriz afro os animais abatidos não sentem dor, como os que são sacrificados nos frigoríficos, e que por isso esse termo seria mais adequado. A relação "antiguíssima, milenar, da reza com a expressão corporal" como parte da relação com o Orixá também foi abordada de forma detalhada no curso, e ao fim de sua aula Bokùlê preparou acarajés enquanto explicava aos alunos sobre a importância da culinária para o candomblé.

O quarto módulo, "Sociedades e Cosmovisões", ocorreu nos dias 28 e 29 de junho, no Instituto de Antropologia, e foi ministrado por Jaqueline Michele Larre Guterres, ou Mãe Michele de Oxum, única convidada de fora de Roraima, sacerdotisa com 26 anos de iniciação de santo no Batuque do Rio Grande do Sul. Mãe Michele começou muito jovem seus ensinamentos na linha de umbanda e quimbanda, na casa de sua avó paterna que era cacica da terreira do Centro Espírita Reino de Cangira, e aos 14 anos se iniciou na nação Cabinda, aprontada por Pai Sandro de Bará, filho de Pai João Carlos de Oxalá.

Por ser de fora de Roraima e a única representante de uma nação desconhecida para os praticantes do candomblé neste estado, a aula da Michele contou com a presença de Vera de Oxossi e de membros das casas de Tata Bokùlê e Yatylyssa. Em sua aula, Michele apresentou a história da Nação Cabinda, enfatizando, igualmente aos demais mestres, os Orixás como forças da natureza. Michele de Oxum explicou que o batuque do Rio Grande do Sul cultua apenas os Orixás, sendo a umbanda e quimbanda as religiões dos espíritos, dos caboclos, preto velhos, ciganos e exús. Como nas aulas anteriores, a culinária foi um aspecto central, levando Michele a afirmar que o "batuque começa na cozinha", pois para ser um bom filho de santo é preciso aprender a comida de cada Orixá.

Uma diferença que despertou a atenção dos alunos e dos adeptos do candomblé que participaram da aula foi a questão dos "cavalos de santo", pessoas ocupadas pelos Orixás que, no caso do batuque, não possuem consciência dessa ocupação. De acordo com Michele, quem recebe o seu Orixá não pode saber, e isso ocorre para que a pessoa não tenha vaidade nem se sinta superior às demais, pois os "Orixás não tem vaidade", e assim a nação cabinda se 
juntou ao vodu e as pessoas que recebiam os Orixás passaram a não saber se eram ocupadas. Рara isso, foi criada uma entidade chamada axero, que é intermediária entre o Orixá e a pessoa. Então quando o Orixá chega no corpo do filho, dança no batuque ou trabalha em uma obrigação, para ir embora ele dá passagem para essa outra entidade chamada axero.

Michele apresentou aos alunos seu jogo do Ifá e falou do Orixá de Orumilaia, que é responsável pelo axé da visão, sendo o "dono dos búzios". Diferente do jogo da mãe Vera, que possui 16 búzios, o ifá de Michele possui apenas 8 búzios, dispostos cuidadosamente em torno de uma moeda, circundado por uma grande guia de miçangas representando todos os Orixás do panteão do batuque. Durante sua explicação sobre como funciona o jogo de búzios na cabinda, Michele jogou o Ifá na presença de todos os alunos, perguntando sobre o projeto do Encontro de Saberes. Como resposta, Xapanã respondeu que ainda haverá guerras religiosas em Roraima, mas que lansã com seus ventos junto com Xangô ajudariam para que o projeto desse certo e para que cada um dos presentes pudesse falar sobre as religiões afro para as pessoas, divulgando esses saberes. Como fechamento dos módulos sobre religiões de matriz africana, Michele tratou em detalhes do ritual de morte no batuque, chamado arissum, e preparou um amalá, comida de Xangô que foi servida a todos os presentes.

O último módulo, "Linguagens e Narrativas", ocorreu nos dias 5 e 6 de julho, no Instituto de Antropologia, e foi o único ministrado por um sábio indígena. Vicente Castro Ihuruana, mestre responsável pelo curso, é um profundo conhecedor dos cantos e histórias dos Ye'kwana, povo de língua caribe habitante da região noroeste de Roraima. Vicente nasceu em uma aldeia à beira do rio Cunucunuma na Venezuela, mudando-se ainda jovem para Fuduuwaduinha, aldeia localizada no rio Auaris, no lado brasileiro. Nos anos 1970, viajou até as comunidades de Fadawainha e Acanaña na Venezuela, onde aprendeu a ler e escrever com os missionários evangélicos, na primeira escola criada em uma comunidade Ye'kuana. Anos depois, visitou a comunidade de Santa Maria do Erebato, onde continuou seu aprendizado da escrita com os missionários católicos, enquanto estudava com os sábios (inchonkomo) a tradição ancestral Ye'kwana. Foi experienciando o contato com os brancos ( ladanawe) e imergindo nas tradições de sua própria cultura, que Vicente Ihuruana se utilizou da escrita na língua vernácula para registrar os conhecimentos Ye'kuana no papel e memorizá-los, sendo hoje considerado o "último conhecedor de memória" das tradições ancestrais desse povo. Em sua aula, Vicente Castro falou sobre a cosmologia de seu povo chamada Watunna, a importância dos cantos denominados a'chudi e das plantas de poder para os processos de cura Ye'kwana. Ao fim do seu módulo, todos puderam provar do refrescante chibé e da tradicional damorida (caldo de peixe). 
Na avaliação final, alguns alunos escreveram poemas, outros relatos escritos e/ou visuais sobre os módulos. A perspectiva dos alunos pode ser sintetizada no trecho final do relato de Sara Lopes Dias, acadêmica do primeiro semestre de antropologia da UFRR:

Os conhecimentos que adquiri dessas religiões foram muito importantes para minha vida pessoal como também para minha vida acadêmica em antropologia. (...) Foi o meu primeiro contato com essas religiões, das quais, tinha receio e medo por passar a vida inteira sendo ensinada que essas religiões praticam o "mal". Com o decorrer das aulas, fui adquirindo mais interesse nos ensinamentos e aprendendo com esses mestres que, independente de sua fé religiosa, todos devem ser respeitados no mesmo nivel de igualdade social e religiosa. Com o contato pela primeira vez com essas religiões, compreendi que todas elas são diferentes, mesmo que em seus pequenos detalhes sejam iguais, como o uso de colares de miçangas, plantas como curas medicinais e ritualísticas. As noções de diferença entre uma religião afro-brasileira e indígenas são muitas, considerando o fato de ambas terem suas próprias histórias e culturas diferentes. A áurea transmitida ao chegar nos terreiros é leve e singela. Há toda uma paz de espírito que consegui sentir ao explorar a casa de santo. O divertido das aulas foi ter a participação dos alunos nas práticas que são feitas quando ocorrem do jeito que foi vivenciado na casa do Tata Bokùlê, de experimentar as comidas dos Orixás e de levar lembranças, tal como ocorreu no terreiro da Mãe Yatylyssa. Um momento mágico e memorável foi quando a Mãe Michele de Oxum previu acontecimentos futuros da turma. A parte mais delicada de todos os encontros, passou-se no dia em que a Vera de Oxóssi completou 30 anos de iniciada no Candomblé Ketu sensibilizando toda turma.

Uma questão relevante a ser considerada nessa primeira oferta da disciplina "Artes e ofícios dos saberes tradicionais" na UFRR foi a ênfase nos saberes tradicionais de matrizes afro brasileiras com a participação de quatro mestres, cada um deles de uma nação diferente, o que possibilitou aos alunos pensarem sobre as diferenças e também semelhanças dessas nações. Ao mesmo tempo, as reflexões dos alunos, alguns deles indígenas, em muitos momentos foram de aproximação dos saberes dos candomblés e do batuque com os saberes indígenas, enfatizando a importância da natureza e das relações de alteridade para essas epistemes.

\section{ENCONTRO DE SABERES NA FURG}

O primeiro contato de professores da FURG com o Projeto Encontro de Saberes, por meio dos antropólogos Pablo Albernaz e José Jorge de Carvalho, deu-se no âmbito do projeto de pesquisa "Letramento acadêmico: práticas de escrita com vistas à inserção e permanência de alunos indígenas e quilombolas na universidade", desenvolvido em 2018 e 2019 no Instituto de Letras e Artes (ILA) na Universidade Federal de Rio Grande (FURG), estado do Rio Grande do Sul. Compreendendo, tal qual Zavala (2010, p. 81), que "as formas de escrita caminham juntas às formas de pensar e as operações cognitivas envolvidas são inseparáveis da compreensão subjetiva e contextualizada que a pessoa faz do mundo", isto é, que os sujeitos se constituem nas relações interpessoais que estabelecem ao longo de sua datação histórica por intermédio de textos orais e/ou escritos, o ingresso no espaço universitário por parte de indígenas e quilombolas significa mais que a aquisição de aspectos 
técnicos de leitura e escrita. Engloba a apropriação de valores, atitudes, crenças, perspectivas, condutas, raciocínios e outros envolvidos na aquisição de novas práticas discursivas, especialmente daquelas materializadas em gêneros do discurso secundários (BAKHTIN, 2010 [1952-53]), podendo acarretar em um conflito identitário por parte dos ingressantes e em uma possível desvalorização das suas formas primárias de ser, de pensar, de interagir, de significar. Nesse cenário, o desafio que se nos apresentou enquanto docentes atentos à singularidade de nossos alunos nos levou a interrogar: como reconhecer e valorizar a plurivocalidade e a diversidade de epistemologias trazidas por eles à universidade?

Na Universidade Federal do Rio Grande, nessa época, havia três coletivos de estudantes: Coletivo Indígena, Coletivo Quilombola, Coletivo Macanudos de Negros e Negras de Rio Grande. Todos participaram da organização do / Seminário Institucional do Encontro de Saberes, que aconteceu em 2018 como um espaço de discussão a fim de propor às Próreitorias de Graduação, de Assuntos Estudantis e de Extensão a criação de uma disciplina optativa oferecida em caráter interdisciplinar no currículo do Curso de Artes Visuais. A sugestão da gestão foi que fizéssemos as primeiras versões na forma de um Projeto de Extensão: Seminário de Encontro de Saberes para, posteriormente, pensar na viabilidade de criar uma disciplina.

Esse Seminário, realizado de 11 a 14 de julho de 2018, contou na parte da manhã com as falas do professor da UFRR e antropólogo Pablo Albernaz e do cacique da aldeia Mbya Guarani Y'yrembé (Beira Mar), Eduardo Ortiz, com mediação do Professor Alfredo Martin, professor aposentado do Curso de Psicologia e responsável pela disciplina de Psicologia Transcultural, que, desde o ano de 2011, convida mestres e sábios dos povos tradicionais para ministrar aulas na universidade.

Na parte da tarde, houve uma grande roda de conversa, com alunos e lideranças estudantis do Coletivo Indígena e do Coletivo Quilombola, do grupo de Capoeira da FURG e do Núcleo de Estudos Afro-brasileiros e Indígenas (NEABI-FURG), representado pelos seus pesquisadores de iniciação científica e por sua coordenadora, Prof. Dra. Cassiane Paixão. Nesse momento, estudantes indígenas e quilombolas apresentaram suas pesquisas em andamento, seus TCC, dissertações e teses: Percepção do idoso indigena kaingang acerca de suas práticas de cuidado (2018), de Ismael Cardoso, kaingang, Enfermagem; Memórias do Nacional Futebol Clube da Aldeia Pinhalzinho no Município de Planalto/RS (2018), de Gílson Morais, guarani, Educação Física; O direito à titulação das terras quilombolas, uma conquista trazida na Constituição de 1988 (2018), de Madaliza Nascente, quilombola, Direito; Da educação quilombola a uma pedagogia quilombola: desafios no horizonte da educação popular (2018), de Angélica da Silva Pinto, quilombola, Pedagogia; Coletivo Macanudos: espaço de 
acolhimento e resistência. "SobreVivências" dos alunos negros no espaço universitário, de Charlene da Costa Bandeira (2019), quilombola, Psicologia.

Esse mesmo Seminário continuou em 29 de setembro, com um módulo chamado "O cuidado da Vida", em uma visita à aldeia guarani Y'yrembé (Beira Mar), na qual quatro sábios indígenas (o kujá kaingang Jorge Kagnan Garcia, de 96 anos, e sua esposa a kujá kaingang Maria Constante da Silva, de 92 anos, junto ao karaí mbya Teófilo Santacruz e sua esposa cunhã karaí Agostina Santacruz) palestraram a uma roda de estudantes e professores dos cursos de Psicologia, Letras e Artes Visuais sobre como, em suas comunidades, acontece o cuidado com a saúde física, mental e espiritual. Falaram especialmente sobre o cuidado com a água, fonte de vida, e a preservação das florestas, fonte de toda a medicina natural dos povos indígenas.

O último módulo deste seminário, em 24 de novembro de 2018, foi uma "Oficina de Música e Capoeira" com a vinda do Mestre Churrasco (João Batista Cléber Teixeira Santos), um dos mestres pioneiros da capoeira no Rio Grande do Sul, chamado o mestre "berimbauzeiro". Mestre Churrasco, o criador do "tririmbau", deu uma aula no curso de Educação Física contando sua trajetória na capoeira e explicando sobre os toques e confecção de diferentes tipos de berimbau. Para um grande círculo de estudantes no Centro Esportivo da FURG, Mestre Churrasco contou sobre seu início na capoeira no cais da Usina do Gasômetro na cidade de Porto Alegre nos anos 1970, depois de suas andanças pelo Brasil e sua relação com os grandes mestres da Bahia.

Um dos mais hábeis e criativos fabricantes de instrumentos para a capoeira, o mestre explicou aos alunos de onde sai a matéria-prima para fazê-los: a natureza. Disse que costuma dar um curso chamado "capoeira na capoeira", quando leva os estudantes para o meio da mata, para caminhar em trechos de mato sem trilha, subindo em árvores, buscando plantas medicinais, aprendendo sobre cabaças, cipós, etc. "É um treinamento ecológico", ele diz; "não como esses de academia". O nosso encontro terminou com uma roda, no Centro de Convivência da FURG, da qual participaram não só o Grupo de Capoeira da FURG como estudantes de vários cursos e o mestre, incansável, que jogou com cada um deles.

No ano de 2019, ainda no formato de Projeto de Extensão, fizemos o // Seminário de Encontro de Saberes, e os estudantes do curso de Engenharia Civil foram convidados a participar do módulo "Arquitetura Tradicional e Cosmologia Mbya Guarani", em uma aula na aldeia Y'yrembé, "com a mão na massa" para a construção de uma casa tradicional mbyá guarani, importante referência de construção sustentável e integrada à natureza. Como explicou o cacique Eduardo Ortiz aos alunos nessa aula prática, a casa guarani é construída sem usar um único prego; apenas com taquara, cipó, barro, palha, madeira ou mesmo xaxim (em algumas regiões da Mata Atlântica). Os estudantes puderam eles mesmos preparar o barro e com ele rebocar as paredes feitas de taquara. O telhado, também feito de taquara 
batida e amarração com cipós, e o fogo sempre aceso garantem conforto térmico à casa guarani. As camas, elevadas um metro do solo, ficam longe do contato com animais e do frio do solo de chão batido.

O cacique Eduardo também explicou sobre tipos de madeira e de cipó, materiais construtivos, posição solar, proteção, sempre relacionando cada elemento da natureza a aspectos da mitologia desse povo. Por exemplo: relatou que as casas são construídas com a porta virada para o Leste, para que a luz do sol (Nhamandú) entre nas casas e as ilumine logo pela manhã. Informou também que as constroem na fase da lua cheia, porque acreditam que isso acarreta uma durabilidade maior da construção.

Depois da aula, o grupo preparou coletivamente um churrasco de chão e passeou por uma trilha aberta na mata, onde pôde conhecer modelos diferentes de armadilhas (arapucas) que os mbya guarani usam para caçar pequenos animais que lhes servem de alimento (pequenas aves, tatus, quatis, etc.). Nos relatórios feitos pelos estudantes, eles ressaltaram a diferença na construção de moradias para os não-indígenas e para os guarani, que veem muito além da estrutura; constroem seguindo uma arquitetura tradicional que preserva suas raízes culturais. Como afirmou uma aluna do curso: "Um engenheiro realiza construções por meio de cálculos e análises, enquanto os mbyá conseguem realizar a mesma função através de orientação cosmológica e religiosa. Em apenas uma visita a esse povo fomos capazes de notar diferenças e deixar de lado nossos preconceitos".

No módulo "Saberes afrocentrados", houve uma saída de campo de três dias, 4 a 6 de outubro, com alunos de Artes Visuais e Letras para o Maçambique de Osório, um dos tipos de congada gaúcha (os outros são Ensaios de Promessa de Quicumbi, nas cidades de Mostardas e Tavares, e o Quicumbi, no Rincão dos Pretos, em Rio Pardo). Os estudantes do curso de Artes Visuais, com orientação de seus professores, puderam fotografar, desenhar, pintar a festa, a missa, a procissão, interagindo durante três dias com os devotos, o casal de festeiros, os maçambiques, "dançantes" da Rainha Ginga, Francisca Dias, e do Rei do Congo.

A festa do Maçambique de Osório é um ritual afro-católico de devoção à Nossa Senhora do Rosário, que acontece no Rio Grande do Sul desde o século XIX (PRASS, 2009, p. 39). Ao longo de três dias, enquanto vivenciamos os preparativos para a festa (comes e bebes na casa da Rainha Ginga, ensaios com os instrumentos, preparo das vestimentas, brancas, impecavelmente passadas a ferro), os estudantes registraram por meio de diários de campo, fotografias e pequenas filmagens cada parte do ritual, que envolve também uma festa oferecida pelo casal de festeiros. Todos os dias, os dançantes vêm até a casa da Rainha Ginga (Francisca Dias) para buscá-la para o cortejo, para o pagamento das promessas, as danças e cantos, a procissão, a missa e o almoço, e a grande festa com danças, ritmos e tambores. 
Ainda no ano de 2019, outro módulo, em 19 de outubro, foi "Carpintaria Naval e Pesca Tradicional" com graduandos de Engenharia Naval. Os estudantes pesquisaram embarcações tradicionais de todo o território brasileiro tombadas pelo IPHAN, especialmente a canoa de pranchão, modelo desenvolvido no Rio Grande do Sul em 1885, cujo casco foi construído com 48 a 50 pranchões de cedro, falquejados a enxó e fixados simetricamente uns aos outros com pregos e cavilhas. Na cidade de Rio Grande, sobreviveram as últimas quatro canoas centenárias, restauradas pelo construtor naval José Vernetti. Em visita ao porto de Rio Grande e em um passeio de barco, os alunos puderam entrevistar os mestres que estão transformando os barcos tradicionais da atividade pesqueira em barcos para turismo ou passeio.

\section{CONCLUSÃO: REFLETINDO SOBRE AS EXPERIÊNCIAS DO ENCONTRO DE SABERES NA UFRR E FURG}

Nos últimos anos, vem ocorrendo uma participação cada vez maior de sábios, mestres e mestras dos conhecimentos tradicionais na academia. Na Universidade Federal de Roraima (UFRR), podemos citar como exemplo disso a aula magna ministrada por Davi Kopenawa Yanomami, intitulada "Os xapiri e a ciência da floresta", assistida por mais de mil alunos, em 2016, a primeira ministrada por um sábio indígena na universidade. Além desse evento, em outras ocasiões os/as mestres/as participam de bancas de qualificação ou de conclusão de graduação, mestrado e doutorado, ou de Seminários e Congressos, como conferencistas. Na Universidade Federal do Rio Grande (FURG), o kujà kaingang Jorge Kagnag Garcia, de 96 anos, participou ritualisticamente da defesa de mestrado e doutorado do estudante Darci Emiliano, no curso de Pós-Graduação em Educação Ambiental do Instituto de Educação da FURG, o primeiro doutorando indígena na universidade. Tal prática tem se repetido em muitas universidades brasileiras onde as ações afirmativas propiciam o encontro dos saberes acadêmicos com os saberes tradicionais. Apesar de esse projeto já ter sido institucionalizado em muitas universidades brasileiras, as experiências na UFRR e na FURG ainda restringem-se a iniciativas pontuais de alguns cursos e professores - seja em uma disciplina no curso de Antropologia, seja em um Projeto de Extensão do qual participaram alunos de vários cursos. No entanto, continuaremos buscando alternativas na intenção de que o projeto seja institucionalizado, em consonância com as políticas de ações afirmativas já existentes nessas universidades.

Uma característica que se ressalta nas experiências do Encontro de Saberes é a de mestres e mestras convidados a ministrar suas aulas assumirem uma voz em primeira pessoa do plural, contrapondo-se aos parâmetros de impessoalidade, individualidade e objetividade dos discursos acadêmicos. Além disso, as bases de seus saberes são polifônicos e geralmente 
envolvem afetividade, intuição, memórias, hibridez de gêneros textuais, um "sentipensar" que reúne as múltiplas vozes da coletividade a que pertence o mestre, em consonância com discussão empreendida em Zavala (2010).

Na sociedade moderna, o letramento surge como agente catalisador de mudanças, é sinônimo de "civilização" e carrega um pesado ônus de expectativa. A própria atividade de escrita na cultura ocidental de base europeia privilegia os gêneros do discurso das classes dominantes, deixando à margem outros gêneros (STREET, 2014). A prevalência dos usos orais da língua nas comunidades tradicionais é, dessa forma, subvalorizada na cultura letrada acadêmica. Em geral, associam-se à oralidade aspectos emocionais, informais, contextualizados e ambíguos; no caso dos usos da modalidade escrita, por sua vez, os elementos estariam voltados a um raciocínio abstrato, descontextualizado e lógico. Essa concepção é revestida de certa "neutralidade" e "transparência" enganosas, conforme discute Street (1984). Acerca disso, pontua Carvalho (2018, p. 93):

"Os estudantes cotistas negros e indígenas, agora em muito maior número, demandam o estudo das suas tradições humanísticas próprias que não passam apenas por obras escritas, mas que estão ancoradas principalmente nas suas tradições orais. E se o cânone afro-brasileiro e indígena é basicamente oral, ele apenas poderá entrar nos currículos universitários pela presença dos mestres e mestras que o dominam".

Segundo Carvalho (2018), descolonizar envolve um duplo movimento. Primeiro, desvincular-se do mandato introjetado de repetir o padrão epistêmico ocidental como única referência de conhecimento (científico, artístico, tecnológico). Na medida em que fazemos parte do segmento social (os acadêmicos) cuja missão seria repetir o discurso colonizador eurocêntrico, optamos pelo termo descolonizar, que significa desfazer a obra colonizadora na academia. O segundo movimento seria não de restaurar um momento acadêmico anterior, não colonizado, mas de refundar a universidade, construindo um novo pacto entre todos os grupos da nação: brancos, negros, indígenas, com todos os seus saberes, escritos e orais.

Com esse artigo, buscamos demonstrar que assumir uma política de ação afirmativa em uma instituição de ensino superior implica algumas etapas: a) desconstruir a equivocada crença de que vivemos numa democracia racial, reconhecendo que a sociedade brasileira se construiu de forma excludente sobre o genocídio indígena e o sacrifício de africanos escravizados; b) compreender as razões da desproporção de alunos e professores negros, indígenas e quilombolas no ensino superior comparados ao quantitativo populacional; c) mudar o perfil da produção de conhecimento, discutindo a colonialidade do saber/poder que silencia, inviabiliza e desprestigia as diversas formas de estar/pensar/dizer/ler/escrever dos povos tradicionais.

Assim, defendemos que um paradigma acadêmico pluriepistêmico sustentado no encontro de saberes, transmitidos não apenas pelos atuais docentes (em sua maioria, 
brancos e eurocêntricos), mas pelos mestres e mestras de cada uma das comunidades e dos povos tradicionais, é crucial para uma consequente formação humana - tanto de alunos, quanto de professores -, bem como para a transformação do espaço universitário tendo como norte uma efetiva democratização.

\section{REFERÊNCIAS}

BAKHTIN, Mikhail. Os gêneros do discurso. In: BAKHTIN, Mikhail (ed.). Estética da criação verbal. 5. ed. São Paulo, Editora WMF Martins Fontes, 2010 [1952-1953]. p. 261-306.

BANDEIRA, Charlene da Costa. Coletivo Macanudos: espaço de acolhimento e resistência. "SobreVivências" dos alunos negros no espaço universitário. Trabalho de Conclusão de Curso Universidade Federal do Rio Grande - FURG, 2019.

BARROSO-HOFMANN, Maria. Direitos culturais diferenciados, ações afirmativas e etnodesenvolvimento: algumas questões em torno do debate sobre ensino superior para os povos indígenas no Brasil. Anais do Simpósio Antropologia Aplicada y Políticas Públicas do $1^{\circ}$ Congreso Latinoamericano de Antropologia, Rosário, Argentina, 2005.

BRASIL. Diretrizes Curriculares Nacionais para Educação Escolar Quilombola. MEC/CEB, 2012. BRASIL, Resolução No 08 de novembro de 2012. Brasília, MEC.

BRASIL. Lei $n^{0}$ 10.639, de 9 de janeiro de 2003. Altera a Lei no 9.394, de 20 de dezembro de 1996, que estabelece as diretrizes e bases da educação nacional, para incluir no currículo oficial da Rede de Ensino a obrigatoriedade da temática "História e Cultura Afro-Brasileira", e dá outras providências. Diário Oficial da União, Brasília, DF, 2003.

BRASIL. Lei $n^{0} 11.645$, de 10 de março de 2008. Altera a Lei $n^{0}$ 9.394, de 20 de dezembro de 1996, modificada pela Lei $n^{0} 10.639$, de 9 de janeiro de 2003, que estabelece as diretrizes e bases da educação nacional, para incluir no currículo oficial da rede de ensino a obrigatoriedade da temática "História e Cultura Afro-Brasileira e Indígena". Diário Oficial da União, Brasília, DF, 2008.

BRASIL. Lei $n^{0} 12.155$ de 23 de dezembro de 2009. Dispõe sobre a concessão de Bônus Especial de Desempenho Institucional - BESP/DNIT aos servidores do Departamento Nacional de Infra-Estrutura de Transportes - DNIT; altera as Leis nos 11.171, de 2 de setembro de 2005, 10.997, de 15 de dezembro de 2004, 11.907, de 2 de fevereiro de 2009, e 11.507, de 20 de julho de 2007; e dá outras providências. Diário Oficial da União, Brasília, DF, 2009.

BRASIL. Lei $n^{0} 12.711$, de 29 de agosto de 2012. Dispõe sobre 0 ingresso nas universidades federais e nas instituições federais de ensino técnico de nível médio e dá outras providências. Diário Oficial da União, Brasília, DF, 201.

BRASIL. Resolução CNE/CEB nº 4, de 13 de julho de 2010 - Define Diretrizes Curriculares Nacionais Gerais para a Educação Básica. Disponível em: http://portal.mec.gov.br/escola-de-gestores-daeducacao-basica/323-secretarias-112877938/orgaos-vinculados-82187207/17417-ceb-2012. Acesso em 11.2.2021. 
BRASIL. Resolução CNE/CEB $n^{0}$ 7, de 9 de novembro de 2012 - Altera 0 parágrafo único do art. $2^{\circ}$ da Resolução CNE/CEB $n^{0}$ 2/2004 e 0 art. $3^{\circ}$ da Resolução CNE/CEB $n^{0}$ 2/2006, e inclui a exigência da oferta de Educação Profissional Técnica de Nível Médio e a obrigatoriedade de oferta de aulas de Língua e Cultura Japonesas e de cadastro no censo escolar do Ministério da Educação. Disponível em: http://portal.mec.gov.br/escola-de-gestores-da-educacao-basica/323-secretarias-112877938/orgaosvinculados-82187207/17417-ceb-2012. Acesso em 11.2.2021

BRASIL. Resolução CNE/CEB $n^{0}$ 8, de 20 de novembro de 2012 - Define Diretrizes Curriculares Nacionais para a Educação Escolar Quilombola na Educação Básica. Disponível em: http://portal.mec.gov.br/escola-de-gestores-da-educacao-basica/323-secretarias-112877938/orgaosvinculados-82187207/17417-ceb-2012. Acesso em 11.2.2021.

CARDOSO, Ismael. Percepção do idoso indígena kaingang acerca de suas práticas de cuidado. Rio Grande, RS. Trabalho de Conclusão de Curso. Universidade Federal do Rio Grande - FURG, 2018.

CARVALHO, José Jorge de. Encontro de Saberes e descolonização: para uma refundação étnica, racial e epistêmica das universidades brasileiras. In: J. BERNARDINO-COSTA; Nelson. MALDONADO-TORRES; GROSFOGUEL, Ramón (ed.). Decolonialidade e pensamento afrodiaspórico. 1. ed. Belo Horizonte, Autêntica Editora, 2018.

CARVALHO, José Jorge. (org.) Encontro de Saberes nas Universidades: bases para um diálogo interepistêmico. Documento-base do seminário. Brasília: INCTI, 16 e 17 de junho de 2015.

CARVALHO, José Jorge. Sobre o Notório Saber dos Mestres Tradicionais nas Instituições de Ensino Superior e de Pesquisa. Cadernos de Inclusão, No. 8. Brasília: Instituto de Inclusão no Ensino Superior e na Pesquisa/UnB, 2016.

CESAR, América.; MAHER, Terezinha. Políticas linguísticas e políticas de identidade em contexto indígena - uma introdução. Trabalhos Em Linguística Aplicada, v. 57, n. 3, p. 1297-1312, 2018. http://dx.doi.org/10.1590/010318138653792446711

FREITAS, Ana Elisa de Castro (org.). Intelectuais indígenas e a construção da universidade pluriétnica no Brasil: povos indígenas e os novos contornos do programa de educação tutorial/conexões de saberes. 1. ed. Rio de Janeiro, E-papers, 2015.

IFASEYÍ, Vera. Diário de área: memórias de uma viagem às terras Yanomami. Boa Vista, RR: Ed. da Aurora, 2021.

MORAIS, Gílson. Memórias do Nacional FC da Aldeia Pinhalzinho no Município de Planalto/RS. Rio Grande, RS. Trabalho de Conclusão de Curso. Universidade Federal do Rio Grande - FURG, 2018.

NASCENTE, Madaliza. 0 direito à titulação das terras quilombolas, uma conquista trazida na Constituição de 1988. Trabalho de Conclusão de Curso. Faculdade de Direito. Universidade Federal do Rio Grande, 2018.

PRASS, Luciana. Maçambiques, Quicumbis e Ensaios de Promessa: um re-estudo etnomusicológico entre quilombolas do sul do Brasil. Tese de Doutorado em Música - Universide Federal do Rio Grande do Sul, 2009. 
PINTO, Angélica da Silva. Da educação quilombola a uma pedagogia quilombola: desafios no horizonte da educação popular. Trabalho de Conclusão de Curso. Universidade Federal do Rio Grande - FURG Instituto de Educação - Curso de Pedagogia Licenciatura, 2018.

PONSO, Letícia Cao. Letramento acadêmico indígena e quilombola: uma política linguística afirmativa voltada à intercultura-lidade crítica. Trabalhos em Linguística Aplicada, v. 57, p. 1512-1533, 2018.

SILVA, Petronilha B.; SILVÉRIO, Valter R. (orgs.). Educação e ações afirmativas: entre a injustiça simbólica e a injustiça econômica. Brasília: INEP, 2003.

SITO, Luanda R. S. Escritas afirmativas: estratégias criativas para subverter a colonialidade em trajetórias de letramento acadêmico. Tese de doutorado - Universidade Estadual de Campinas Unicamp, 2016.

STREET, Brian. Letramentos sociais: abordagens críticas do letramento no desenvolvimento, na etnografia e na educação. São Paulo, Parábola Editorial, 2014.

ZAVALA, Virgínia. Quem está dizendo isso?: letramento acadêmico, identidade e poder na educação superior. In: VóvIO, Cláudia; SITO, Luanda; GRANDE, Paula de (ed.). Letramentos: rupturas, deslocamentos e repercussões de pesquisas em linguística aplicada. Campinas, SP, Mercado de Letras, 2010. p. 71-98.

Recebido em 01 de setembro de 2020. Aprovado em 01 de fevereiro de 2021. 